\title{
USE OF ANTIGENIC RELATIONSHIPS TO DIFFERENTIATE AMONG ISOLATES OF Macrophomina phaseolina AND TO STUDY THEIR PATHOGENICITY ON COTTON \\ Hussein, E.M. ${ }^{1}$; Aly, A.A. ${ }^{1 ;}$, M.A. Abdel-Sattar ${ }^{2}$ and M.R. Omar ${ }^{1}$ \\ 1 Plant Pathology Research Institute, Agric. Res. Center, Giza, Egypt. \\ 2 Dept. of Agric. Bot., Faculty of Agric., Suez Canal Univ., Ismailia, Egypt.
}

\section{ABSTRACT}

Isolates of Macrophomina phaseolina were classified into groups by cluster analysis based on their antigenic composition; however, grouping the isolates was not related to their virulence, geographic origin, or host. Cotton cultivar Giza 75 and the most pathogenic isolates from cotton were placed in a separate cluster based on their antigenic composition. The relationship between common antigens, shared by Giza 75 and cotton isolates, and pathogenicity of these isolates was quantified by correlation and regression analyses. There was a positive significant correlation $(r=$ $0.91, p<0.05$ ) between simple matching coefficient (SSM), established between $M$. phaseolina isolates and Giza 75, and pathogenicity of the isolates on this cultivar. The regression model indicated that SSM accounted for $84 \%$ of the total variation in pathogenicity of the isolates. These results imply that the common antigenic determinants shared by cotton and $M$. phaseolina isolates are related to severity of charcoal rot.

\section{INTRODUCTION}

Macrophomina phaseolina (Tassi) Goid., the causal agent of charcoal rot (ashy stem) on cotton, is a seed-borne and soil-borne pathogen with a wide distribution and a wide host range (Dhingra and Sinclare, 1978). When M. phaseolina invades roots or stems of cotton, colonization of internal tissues proceeds rapidly and the plant dies. Examination of affected parts reveals a dry rot, with many tiny black sclerotia distributed throughout the wood and softer tissues (Watkins, 1981). A negative correlation $(r=-0.85, p$ $<0.01$ ) was found between disease incidence and yield (Turini et al., 2000).

M. phaseolina is of a widespread distribution in the Egyptian soil, and it is easily and frequently isolated form cotton roots particularly during the late period of the growing seasons. Thus, when Aly et al. (1996) conducted a survey encompassed 88 samples of infected cotton roots from 12 governorates, $M$. phaseolina was isolated from $37.5 \%$ of the samples examined.

Although initial infections of cotton by M. phaseolina occur at the seedling stage, they usually remain latent until the cotton plant approaches maturity (Dhingra and Sinclare, 1978). However, M. phaseolina appears to affect some cotton cultivars less severly than others, suggesting the existence of some level of resistance to $M$. phaseolina (Watkins, 1981; Lee et al., 1986; Monga and Raj, 1996 and 2000, and Turini et al., 2001). In Egypt, resistance to $M$. phaseolina is completely lacking in the commercial cottons (Gossypium barbadense L.) (Aly et al., 2006). 
Differentiation among $M$. phaseolina isolates pathogenic on cotton is important for improving our understanding of the ecology of these isolates and the epidemiology of the disease. The conventional method of differentiation among pathogen isolates is the observation of the differences in virulence when the isolates interact with a set of host genotypes (Aly, 1988; Ahmed et al., 1991; Schilder and Bergstrom, 1990, and Porta-Puglia et al., 1996). However, this method is expensive, time consuming, and may be influenced by variability inherent in the experimental system (Aly, 1988 and Bhatti and Kraft, 1992). Furthermore, the differential disease reactions do not provide information about the genetic relationship among the pathogen isolates (Perez-Artes et al., 1995).

Therefore, another reliable method, either alternative or complementary to that based on the differential interaction between $M$. phaseolina isolates and cotton genotypes, is required for identification of $M$. phaseolina isolates pathogenic on cotton.

Serology is one of the biochemical techniques proposed as being useful in fungal taxonomy. There are many papers in the literature reporting the serological separation of fungal species, formae speciales, isolates, or physiological races. For example, Hornok (1980) used immunoelectrophoresis in a study of 13 Fusarium species belonging to sections Discolor and Gibbosum, with two or three strains representing each species. Four groups were evident, corresponding with section Gibbosum, section Discolor and with $F$. buharicum and $F$. heterosporum coming out as different from all the others. The results. Therefore, corresponded with morphological view of the genus. lannelli et al. (1982) showed that $F$. oxysporum, $F$. moniliforme, and F. xylarioides possessed distinct antigenic characteristics. In addition, they describe how four different formae speciales of $F$. oxysporum (dianthi, melonis, pisi, lycopersici) and the physiological races of $F$. oxysoprum f.sp. melonis (races 1, 2, 3) can be differentiated by serological techniques. Rataj-Guranowska et al. (1984) compared between race 2 and race 3 of $F$. oxysporum f.sp. lupini by tandum-crossed immunoelectrophoresis. They found that the two races had apparently almost identical antigenic patterns differing only in one antigen specific to race 3 . Barak et al. (1985) raised antisera against conidia of several Trichoderma isolates in rabbits and tested them by agglutination and immunofluorescence. Six serotypes were characterized and the differences in their surface properties studied. The serological differences among the isolates did not always reflect their taxonomic differences. Serological similarities were found in several instances between conidia and hyphae of the same isolate. RatajGuranowska and Wolko (1991) compared F. oxysporum and F. oxysporum var. redolens serologically. Although their results indicated a strong similarity between the two fungi, they were not sufficient for an unequivocal statement that fungi belong to the same species. Hussein et al. (1996) compared $F$. oxysporum, F. moniliforme, and F. solani, isolates from cotton seedlings infected with damping-off, by double diffusion (DD) and immunoelectrophoresis (IE) techniques to determine their serological relationships. On the basis of serological relationships, isolates were grouped by cluster analysis and the results were expressed as phenograms. The 
taxonomic relationships established based on DD matched those based on modern system of morphological classification. DD technique in comparison with IE technique, proved to be more sensitive as a serotaxonomic tool provided that the use of specific antigens for comparisons in combination with cluster analysis of the resulting similarity indexes. Kratka et al. (1997) studied specificity and sensitivity of polyclonal antibodies after immunization of rabbits with antigens of 18 monospore isolates of $F$. culmorum (FCU). Antigens of FCU isolates showed similar reactions. Anti-FCU IgG reacted with antigens of other Fusarium spp. (F. oxysporum, F. solani, F. equiseti, F. nivale, $F$. sambucinum, $F$. poae, $F$. avenaceum). Differences were quantitative. Reactions of antisera and IgG with antigens were evaluated by agar double diffusion and ELISA.

In several instances, it has been found that plant hosts have antigenic substances in common with parasitic microorganisms. These substances have been termed "Common antigens" (Charudattan and DeVay, 1972). One of the theories that have been proposed to explain the primary factor in the plant-parasite interaction, which would lead either to susceptibility or resistance of the plant, is the degree of antigenic parity between the plant and the pathogen. According to this concept, the greater the antigenic parity between the plant and the pathogen, the greater will be susceptibility of the plant to the pathogen (Wimalajeewa and DeVay, 1971). It seems that the presence of common antigens may be an important factor that prevents triggering of the plant defense mechanisms, thus allowing the pathogen to parasitize the plant (Charudattan and DeVay, 1972).

Many experimental results lend support to the previously mentioned theory. For instance, Purkayastha and Chakraborty (1983) tested 10 soybean cultivars against $M$. phaseolina. Soymax was the most susceptible and UPSM-19 the most resistant. Agar-gel diffusion tests revealed common antigenic relations between susceptible plants and $M$. phaseolina. Immunoelectrophoresis showed that 4 common antigenic substances occurred in susceptible cultivar-pathogen combinations but none in resistant combinations. Purkayastha and Ghosal (1987) obtained antigens from two isolates of M. phaseolina, 4 non-pathogens of groundnut (Corticium sasakii, Colletotrichum lindemuthianum, C. corchori, and Botrytis alii), and 5 groundnut cultivars. The antigens were compared by immunoduffusion, immunoelectrophoresis, and crossed-immunoelectrophoresis for the presence of cross-reactive antigens. Common antigens were found among the susceptible groundnut cultivars and 2 isolates of $M$. phaseolina, but not between non-pathogens and groundnut cultivars. No antigen similarity was found between non-pathogens and $M$. phaseolina isolates. Crossedimmunoelectrophoretic tests confirmed that at least 1 antigen was common between cV. J-11 and cv. TMV-2, cv. Kadiri 71-1 and cV. TMV-2, and cv. Kadiri 71-1 and isolates of $M$. phaseolina. Chakraborty and Purkayastha (1987) found that sodium azide was the most effective of the 6 metabolic inhibitors tested in reducing charcoal rot disease of soymax soybeans caused by $M$. phaseolina. Cross-reactive antigens were detected in purified preparations from mycelia of $M$. phaseolina with antisera of soybean roots by immunodiffusion and immunoelectrophoretic tests. An antigenic disparity was 
noticed in the susceptible cultivar (Soymax) after chemical induction of resistance. Hussein et al. (1997) compared proteins of $R$. solani (RS) with those of host and non-host plants by double diffusion (DD) test. Cotton, flax, and kenaf were used as host plants, while wheat, barley, and sorghum were the non-host plants. In the reaction of antiserum of RS with homologous antigen and plant antigens, among the four bands formed in the homologous reaction, two were common with the antigens of host plants. No common antigens were shared between RS and any of the non-host plants. It was concluded that the greater the antigenic parity between the host and the pathogen, the greater will be the susceptibility of the host to the pathogen.

The present investigation was initiated to determine whether isolates of $M$. phaseolina can be distinguished by their serological protein patterns (SPPs) separated by double diffusion technique. SPPs were also used to study pathogenicity of the isolates on cotton.

\section{MATERIALS AND METHODS}

\section{Fungal isolates}

Isolates of $M$. phaeolina used in the present study (Table 1) were obtained from the fungal collection of Cotton Disease Research Section, Plant Pathology Research Institute, Agricultural Research Center, Giza, Egypt. The isolates were originally recovered from cotton and other hosts.

Production of $\boldsymbol{M}$. phaseolina inoculum used in soil infestation

Substrate for growth of the isolates was prepared in $500-\mathrm{ml}$ glass bottles, each bottle contained $50 \mathrm{~g}$ of sorghum grains and $40 \mathrm{ml}$ of tap water. Contents of each bottle were autoclaved for 30 minutes. Isolate inoculum, taken from one-week-old culture on PDA, was aseptically introduced into the bottle and allowed to colonize sorghum for three weeks.

Table 1. Isolates of $M$. phaseolina used in serological studies.

\begin{tabular}{lllll}
\hline Isolate & Geographic & Host & \multicolumn{2}{l}{ Infection ${ }^{\text {a } \%}$} \\
\hline 4 & Giza & Cotton & $98^{\mathrm{b}}$ & $\mathrm{A}^{*}$ \\
5 & Daqahlyia & Cotton & 74 & $\mathrm{ABCD}^{*}$ \\
6 & Giza & Cotton & 64 & $\mathrm{CDEF}$ \\
7 & Minofiya & Cotton & 44 & $\mathrm{EF}$ \\
8 & Damiatta & Cotton & 40 & $\mathrm{~F}$ \\
9 & Giza & Sesame & 96 & $\mathrm{~A}^{*}$ \\
10 & Giza & Sesame & 60 & $\mathrm{DEF}$ \\
14 & Giza & Sunflower & 86 & $\mathrm{ABC}^{*}$ \\
15 & Giza & Soybean & 92 & $\mathrm{AB}^{*}$ \\
17 & Giza & Soybean & 72 & $\mathrm{BCDE}$ \\
18 & Giza & Sunflower & 80 & $\mathrm{ABCD}^{*}$ \\
20 & Gharbiya & Cotton & 90 & $\mathrm{ABC}^{*}$ \\
21 & Fayoum & Sesame & 86 & $\mathrm{ABC}^{*}$ \\
Control & & & 38 & $\mathrm{EF}$ \\
\hline
\end{tabular}

a Mean of five replications. Data were transformed into arc sine angles before analysis of variance to obtain approximately constant variance.

b Mean followed by the same letter(s) are not significantly different $(P \leq 0.05)$ according to Duncan's multiple range test..

An asterisk (*) denotes a significant difference from the control. 


\section{Pathogenicity test of M. phaseolina isolates on cotton cultivar Giza 75 (Gossypium barbadense L.)}

Thirteen isolates M. phaseolina (Table 1) were used in the present study. Batches of autoclaved clay loam soil were separately infested with inoculum of each isolate at a rate of $40 \mathrm{~g} / \mathrm{kg}$ soil. The inoculum consisted of mycelia and sclerotia growing on sorghum. Infested soil was dispensed in 10-cmdiameter clay pots and these were planted with 10 seeds per pot for the tested cultivar. In the control treatment, autoclaved sorghum grains were thoroughly mixed with soil at a rate of $40 \mathrm{~g} / \mathrm{kg}$ of soil. Pots were randomly distributed on greenhouse benches under temperature regime ranged from $19.5 \pm 1.5^{\circ} \mathrm{C}$ to $34 \pm 4^{\circ} \mathrm{C}$. Percentage of infected seedlings were recorded 45 days after planting.

\section{Statistical analysis of the pathogenicity test}

The experimental design of the greenhouse study was a randomized complete block with five replicates (pots). Analysis of variance (ANOVA) of the data was performed with the MSTAT-C Statistical Package. Duncan's multiple range test was used to compare between isolate means. Percentages were transformed into arc sine angles before carrying out the ANOVA to produce approximately constant variance.

\section{Extraction of fungal proteins (antigens)}

Protein extracts from $M$. phaseolina isolates were prepared according to Hussein (1992) in the following way: Fungal isolates were grown for 22 days at $22-30^{\circ} \mathrm{C}$ on liquid Czapek medium. The mycelium was harvested by filtration through cheesecloth, washed with distilled water several times, and freeze-dried. This frozen mycelium was suspended in phosphate buffer $\mathrm{pH}$ $8.3(1-3 \mathrm{ml} / \mathrm{g}$ mycelium), mixed thoroughly with glass beads, and ground in liquid nitrogen to a fine powder. The ground mycelium was centrifuged at $19,000 \mathrm{rpm}$ for 30 minutes at $0^{\circ} \mathrm{C}$. The protein content in the supernatant was estimated according to Bradford (1976) by using bovine serum albumin as a standard protein. If protein concentration was low, protein was precipitated from the clarified supernatant by adding ammonium sulphate at $70 \%$ of saturation $(60 \mathrm{~g} / 100 \mathrm{ml})$ then kept in the refrigerator for $30 \mathrm{hr}$. Pellets, collected by centrifugation at $11,000 \mathrm{rpm}$ for 30 minutes, were re-suspended in phosphate buffer $\mathrm{pH} 8.3$ and subjected to dialysis for $24 \mathrm{hr}$. against the buffer and centrifuged at $11,000 \mathrm{rpm}$ for 30 minutes. Protein was estimated in the obtained supernatant.

Immunization and preparation of antiserum of isolate no. 20

A New Zealand rabbit, 3-4 $\mathrm{kg}$ weight was immunized by antigen of isolate no. 20 to produce antiserum. The first injection was given intracutaneously in the back between ears. This injection consisted of $0.5 \mathrm{mg}$ protein suspended in $1 \mathrm{ml}$ phosphate buffer and mixed in $1 \mathrm{ml}$ Freund's incomplete adjuvant. After one week, the animal received $4 \mathrm{mg}$ protein administrated intramuscularly every third day in the thigh in a series of 12 injections. One week after the last injection, the animal was bled and antibodies in serum were assayed by double diffusion technique. 


\section{Double diffusion technique}

The technique was carried out according to Oucheterlony and Nilsson (1978). One percent ionagar, melted in normal saline and supplemented with merthiolate $(1: 10,000)$ was poured into $9-\mathrm{cm}$ diameter Petri dishes to obtain a layer of agar $1-2 \mathrm{~cm}$ thick. The diameters of the central and of the 6 peripheral wells were 5 and $3 \mathrm{~mm}$, respectively. The distance between the central well and the peripheral ones was $15 \mathrm{~mm}$. The central well was filled with the antiserum of the isolate no. 20 and the peripheral wells with the antigens of the other isolates. Plates were kept in humid conditions at room temperature $\left(18-24^{\circ} \mathrm{C}\right)$ in the dark for one week. Agar was stained with Commassie brilliant blue R-250 (Weeke, 1973). The developing precipitin lines were examined and recorded by hand drawing and photography.

\section{Cluster analysis}

Simple matching coefficient (SSM) was calculated for each pair of isolates (Sokal and Michener, 1958). Based on these data, a similarly matrix was constructed and from this matrix isolates were clustered by the average linked technique (unweighted pair-group method). The results were expressed as phenogram (Joseph et al., 1992). Cluster analysis was performed with a computerized program.

\section{Extraction of protein (antigen) of cultivar Giza 75}

Protein was extracted from seeds of cultivar Giza 75 according to Hussein (1992) in the following way: Seeds were slightly ground and defatted by diethyl either or chloroform for 4 or 5 days. After drying at room temperature, ground seeds were suspended in a solution $(1-3 \mathrm{ml} / \mathrm{g}$ seeds) consisting of $12.5 \mathrm{~g}$ glucose and 19 ascorbic acid dissolved in 100 phosphate buffer ph 8.3 and ground in liquid nitrogen to a fine powder. After thawing, the powder suspended in buffer, was centrifuged at $19000 \mathrm{rpm}$ for 30 minutes at $0{ }^{\circ} \mathrm{C}$. The protein content in supernatant was adjusted to a concentration of 3 to $4 \mathrm{mg} / \mathrm{ml}$ according to Bradford spectrophotometeric method (1976) by using bovine serum albumin as a standard protein.

\section{Immunization and preparation of antiserum of cultivar Giza $\mathbf{7 5}$}

Immunization and preparation of antiserum of cultivar Giza 75 were carried out as previously mentioned.

\section{Cluster and regression analyses}

Cluster analysis was carried out as previously mentioned. Regression analysis was used to study the relationship between SSM establishment between isolates of $M$. phaseolina and Giza 75, and pathogenicity of the isolates on this cultivar.

\section{RESULTS AND DISCUSSION}

A total of 13 isolates of $M$. phaseolina from 4 hosts were tested for pathogenicity on seedlings of cotton cultivar Giza 75 under greenhouse 
conditions (Table 1). Cotton isolates (6 isolates) were the predomentant group representing $46.15 \%$ of the tested isolates. Isolates of the other isolates ranged from 2 to 3 . Of the cotton isolates, 3 were pathogenic representing $50 \%$ of the cotton isolates, $23.08 \%$ of the total isolates, and $37.5 \%$ of the pathogenic isolates of all hosts. The pathogenic isolates of the other hosts ranged from 1 to 2 .

Double diffusion tests (Figs. 1-4) were used to establish the common antigen data shown in Table 2. These data were used for calculating simple matching coefficients (SSMs) among 11 isolates of $M$. phaseolina (Table 3). A phenogram (Fig. 5) was constructed based on taxonomic distance (TDs) generated from SSMs. The smaller the TD, the more closely the isolates were related in their antigenic composition. In this phenogram, isolate 5 and 15 belonged to a single cluster $(T D=13.8)$. These two isolates were unrelated to the remaining isolates, which belonged to another cluster (TD = 9 ). This cluster was subdivided into two sub-clusters. The first one ( $T D=0.0)$ was composed of isolates $18,21,6,10,17,7$ and 9 , while the second one $(\mathrm{TD}=0.0)$ was made up of isolates 14 and 20 .

Double diffusion tests (Figs 6-8) were used to establish the common antigen data shown in Table 4. These data were used to construct the phenogram shown in Fig. 9. In this phenogram, Giza 75 and the most pathogenic isolates 4,5 , and 20 constituted a distinct cluster $(T D=7)$. The weakly pathogenic isolates 7 and 8 were found in a separate cluster (TD = 17). This result indicates that the greater the antigenic parity between cotton and $M$. phaseolina isolates, the greater will be the susceptibility of cotton to those isolates. A noteworthy peculiarity in the phenogram is the individuality of the moderately pathogenic isolate 6 , which was unrelated to the other isolates.

The relationship between common antigens, shared by Giza 75 and isolates, and pathogenicity of isolates was quantified by correlation and regression analyses (Fig. 10). There was a positive significant correlation ( $r$ $=0.91, \mathrm{P}<0.05)$ between simple matching coefficient (SSM), established between $M$. phaseolina isolates and Giza 75, and pathogenicity of the isolates on this cultivar. The regression model indicated that SSM accounted for $84 \%$ of the total variation in pathogenicity of the isolates. These results imply that the common antigenic determinants shared by cotton and $M$. phaseolina isolates are related to severity of charcoal rot. The model can be used as a rapid and preliminary screening tool for evaluating pathogenicity of the isolates. However, one should keep in mind that the use of this model is complementary and not an alternative method to the greenhouse test. Evidently, the use of this model would considerably reduce the number of isolates that would be tested in the greenhouse. 

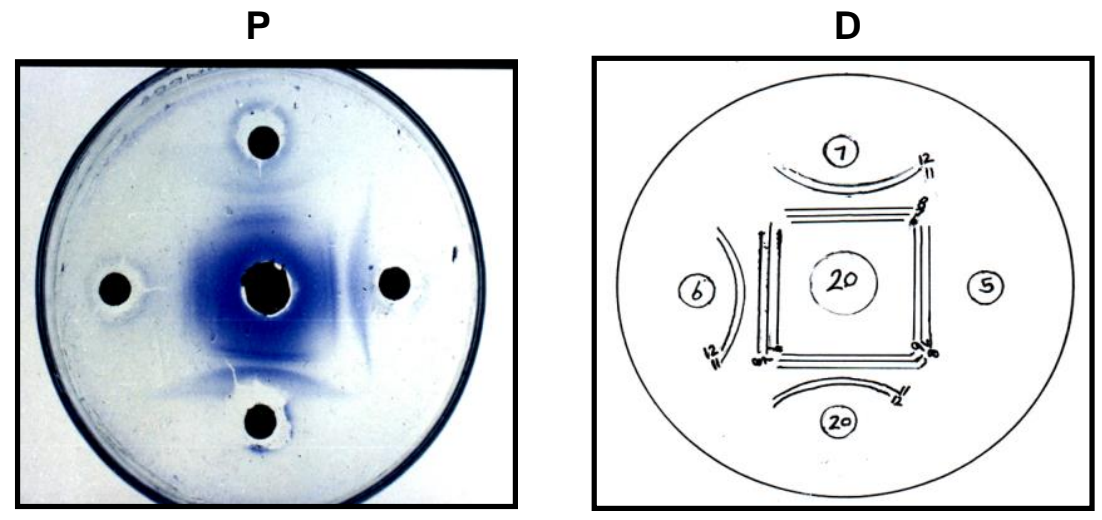

Fig. 1. Photograph (1P) and diagram (1D) showing the double-diffusion reactions of the antiserum of isolate no. 20 of $M$. phaseolina from cotton (in central well) against antigens of isolates nos. 5 , 6,7 and 20 from cotton (in peripheral wells). Antiserum of isolate no. $20 \mathrm{x}$ antigen of isolate no. 20 is homologous reaction.

$\mathbf{P}$

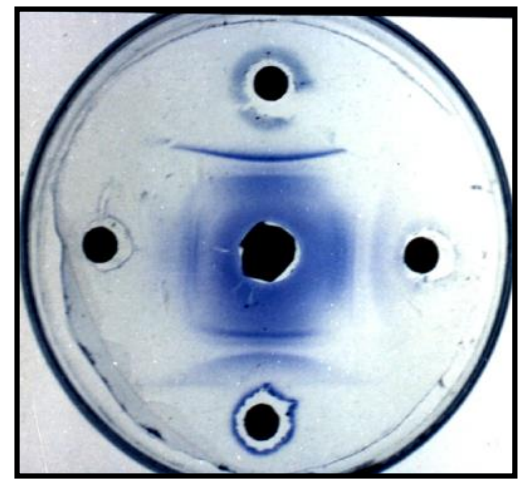

D

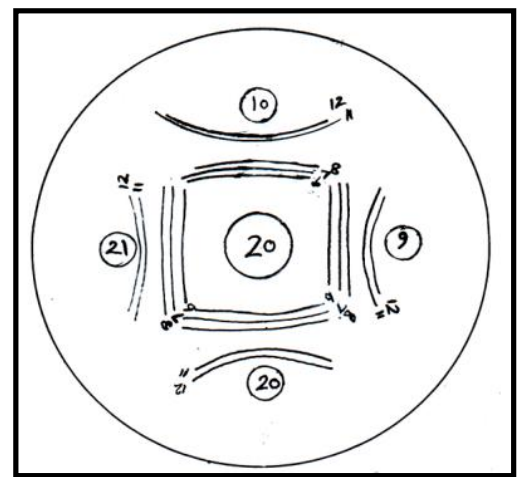

Fig. 2. Photograph (2 P) and diagram (2 D) showing the double-diffusion reactions of the antiserum of isolate No. 20 of $M$. phaseolina from cotton (in central well) against antigens of isolates $\mathrm{no}_{\mathrm{s}} .9$, 10 and 21 from sesame and isolate no. 20 from cotton (in peripheral wells). Antiserum of isolate no. $20 \mathrm{x}$ antigen of isolate no. 20 is homologous reaction. 
$\mathbf{P}$

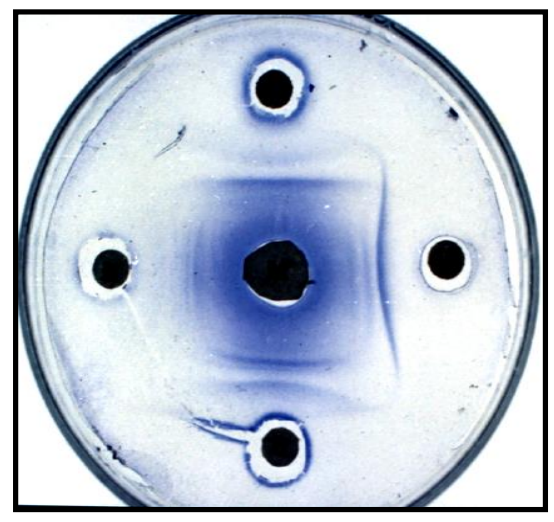

D

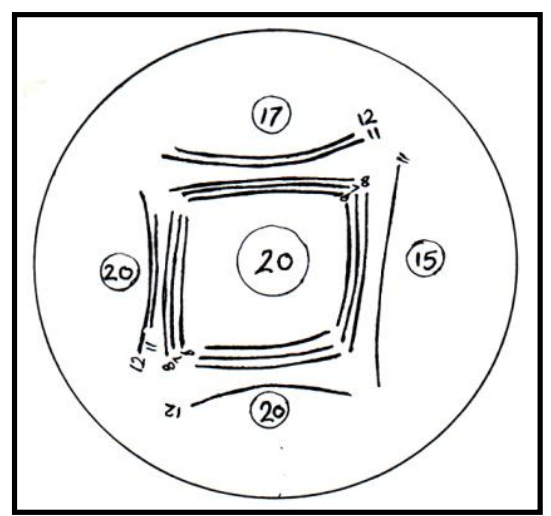

Fig. 3. Photograph (3 P) and diagram (3 D) showing the double-diffusion reactions of the antiserum of isolate no. 20 of $M$. phaseolina from cotton (in central well) against antigens of isolates nos. 15 and 17 from soybean and isolate no. 20 from cotton (in peripheral wells). Antiserum of isolate no. $20 \mathrm{x}$ antigen of isolate no. 20 is homologous reaction.

$\mathbf{P}$

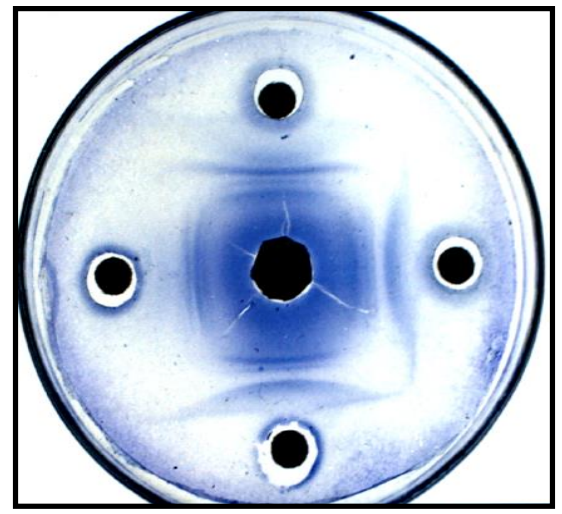

D

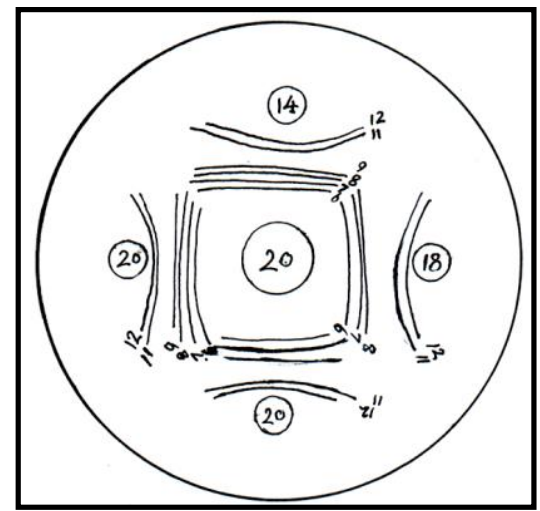

Fig. 4. Photograph (4 P) and diagram (4 D) showing the doublediffusion reactions of the antiserum of isolate no. 20 of $M$. phaseolina from cotton (in central well) against antigens of isolates nos. 14 and 18 from sunflower and isolate no. 20 from cotton (in peripheral wells). Antiserum of isolate no. $20 \mathrm{x}$ antigen of isolate no. 20 is homologous reaction. 
Hussein, E.M. et al.

Table 2. Number and distribution of protein fractions obtained by double-diffusion reaction of antiserum of isolate 20 from cotton against antigens of isolates from cotton, sesame, soybean and sunflower.

\begin{tabular}{|c|c|c|c|c|c|c|c|c|c|c|c|}
\hline \multirow{3}{*}{$\begin{array}{l}\text { Protein } \\
\text { fraction } \\
\text { No. }\end{array}$} & \multicolumn{11}{|c|}{ Antiserum of isolate $20 x$ antigen of } \\
\hline & \multicolumn{4}{|c|}{ Cotton isolate } & \multicolumn{3}{|c|}{$\begin{array}{c}\text { Sesame } \\
\text { isolate }\end{array}$} & \multicolumn{2}{|c|}{$\begin{array}{c}\text { Soybean } \\
\text { isolate }\end{array}$} & \multicolumn{2}{|c|}{$\begin{array}{c}\text { Sunflower } \\
\text { isolate }\end{array}$} \\
\hline & 5 & 6 & 7 & $20 a$ & 9 & 10 & 21 & 15 & 17 & 14 & 18 \\
\hline 1 & + & + & + & + & + & + & + & + & + & + & + \\
\hline 2 & + & + & + & + & + & + & + & + & + & + & + \\
\hline 3 & + & + & + & + & + & + & + & + & + & + & + \\
\hline 4 & - & - & - & + & - & - & - & - & - & + & - \\
\hline 5 & - & + & + & + & + & + & + & + & + & + & + \\
\hline 6 & - & + & + & + & + & + & + & + & + & + & + \\
\hline
\end{tabular}

a Homologous antiserum-antigen reaction.

(+) The designated protein fraction was present.

$(-)$ The designated protein fraction was absent.

Table 3. Matrix containing simple matching coefficients (SSM) ${ }^{a}$ established among 11 isolates of $M$. phaseolina from cotton, sesame, soybean and sunflower when their antigens interacted against antiserum of isolates no. 20 from cotton.

\begin{tabular}{|c|c|c|c|c|c|c|c|c|c|c|c|}
\hline \multirow{2}{*}{$\begin{array}{l}\text { Isolate } \\
\text { No. }\end{array}$} & \multicolumn{11}{|c|}{ Isolate } \\
\hline & 5 & 6 & 7 & 9 & 10 & 14 & 15 & 17 & 18 & 20 & 21 \\
\hline 5 & 100 & 60 & 60 & 60 & 60 & 50 & 75 & 60 & 60 & 50 & 60 \\
\hline 6 & 60 & 100 & 100 & 100 & 100 & 83.3 & 80 & 100 & 100 & 83.3 & 100 \\
\hline 7 & 60 & 100 & 100 & 100 & 100 & 83.3 & 80 & 100 & 100 & 83.3 & 100 \\
\hline 9 & 60 & 100 & 100 & 100 & 100 & 83.3 & 80 & 100 & 100 & 83.3 & 100 \\
\hline 10 & 60 & 100 & 100 & 100 & 100 & 83.3 & 80 & 100 & 100 & 83.3 & 100 \\
\hline 14 & 50 & 83.3 & 83.3 & 83.3 & 83.3 & 100 & 66.7 & 83.3 & 83.3 & 100 & 83.3 \\
\hline 15 & 75 & 80 & 80 & 80 & 80 & 66.7 & 100 & 80 & 80 & 66.7 & 80 \\
\hline 17 & 60 & 100 & 100 & 100 & 100 & 83.3 & 80 & 100 & 100 & 83.3 & 100 \\
\hline 18 & 60 & 100 & 100 & 100 & 100 & 83.3 & 80 & 100 & 100 & 83.3 & 100 \\
\hline 20 & 50 & 83.3 & 83.3 & 83.3 & 83.3 & 100 & 66.7 & 83.3 & 83.3 & 100 & 83.3 \\
\hline 21 & 60 & 100 & 100 & 100 & 100 & 83.3 & 80 & 100 & 100 & 83.3 & 100 \\
\hline
\end{tabular}

Simple matching coefficient (SSM) was determined for each pair of isolates as described by Sokel and Michener (1958) by the following formula:

$\mathrm{SSM}=(\mathrm{m} / \mathrm{m}+\mathrm{u}) \times 100$

where $\mathbf{m}=$ the number of pairs of precipitin lines found in common between the two isolates, and $u=$ the total number of precipitin lines unique to each isolate. 


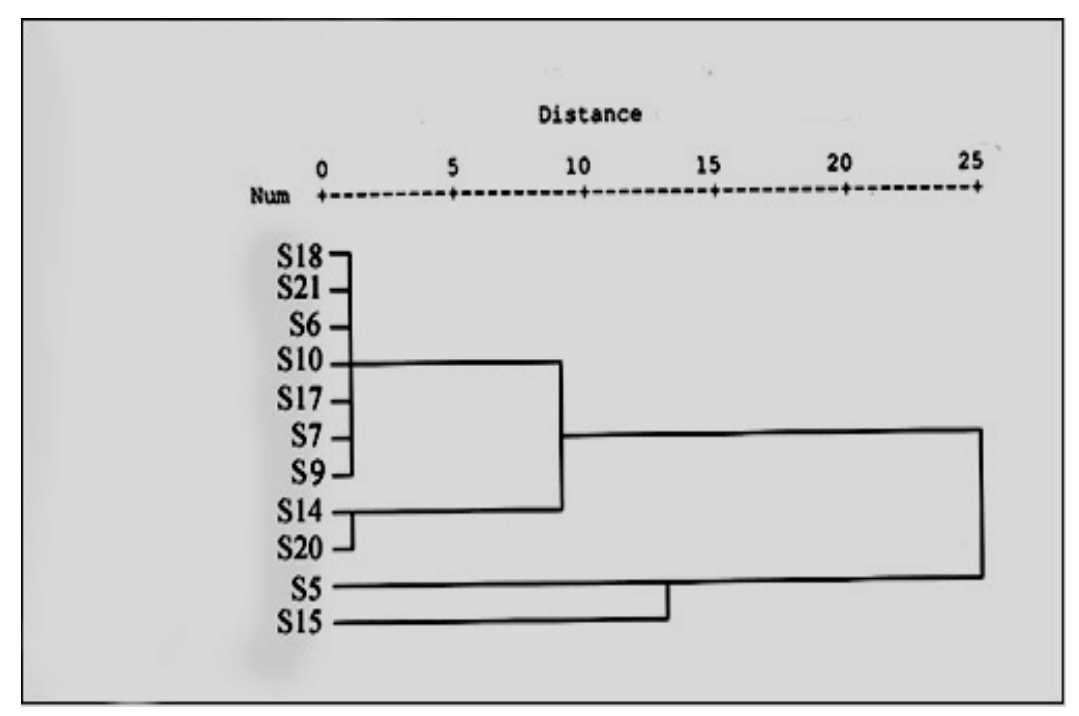

Fig. 5. Phonogram based on average linkage cluster analysis of serological protein patterns obtained by double - diffusion technique from 11 isolates of $M$. phaseolina from different hosts when their antigens interacted against antiserum of isolate no. 20 from cotton. Characterization of isolates is shown in Table 1.

$\mathbf{P}$

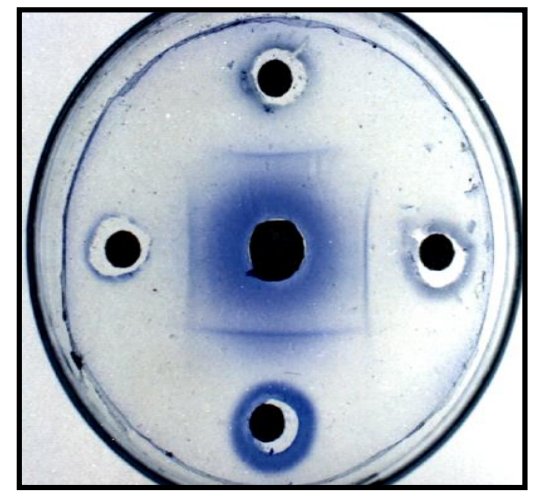

D

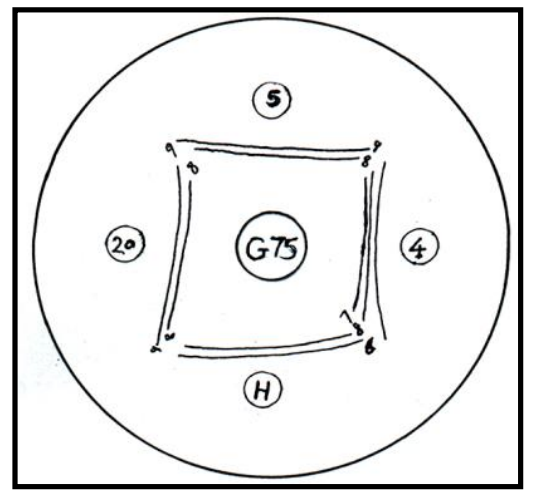

Fig. 6. Photograph (6 P) and diagram (6 D) showing the double-diffusion reactions of the antiserum of cotton cultivar Giza 75 (in central well) against antigens of $M$. phaseolina isolates nos. 4, 5, and 20 from cotton (in peripheral wells). $\mathrm{H}$ the is homologous reaction. 
$\mathbf{P}$

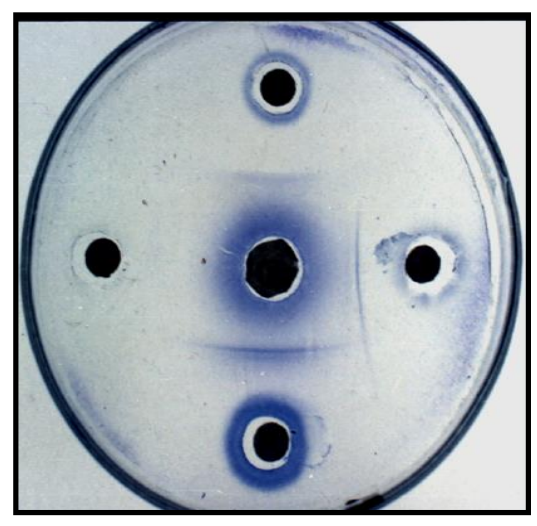

D

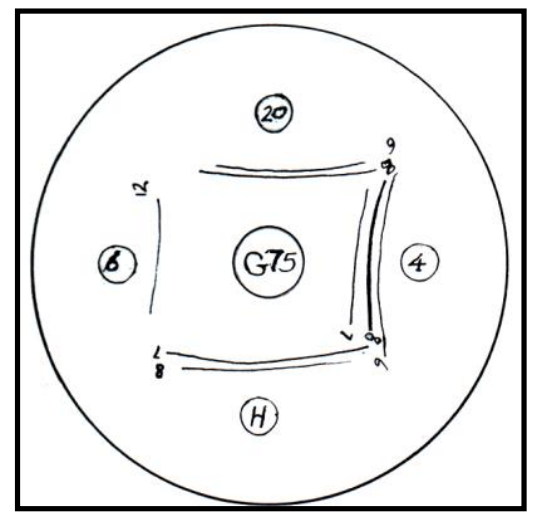

Fig. 7. Photograph $(7 \mathrm{P})$ and diagram $(7 \mathrm{D})$ showing the doublediffusion reactions of the antiserum of cotton cultivar Giza 75 (in central well) against antigens of $M$. phaseolina isolates nos. 4, 6, and 20 from cotton (in peripheral wells). $\mathrm{H}$ the is homologous

$\mathbf{P}$

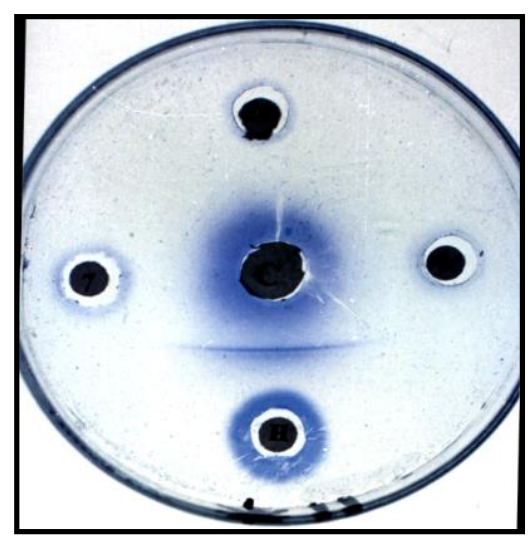

D

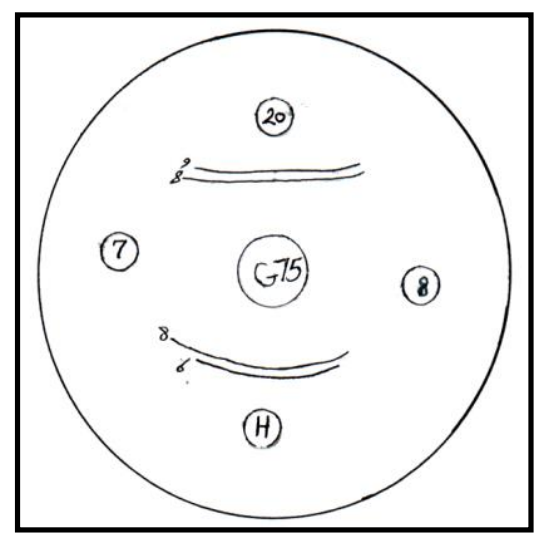

Fig. 8. Photograph (8P) and diagram (8D) showing the double-diffusion reactions of the antiserum of cotton cultivar Giza 75 (in central well) against antigens of $M$. phaseolina isolates nos. 7, 8, and 20 from cotton (in peripheral wells). $\mathrm{H}$ the is homologous reaction. 
Table 4. Number and distribution of protein fractions obtained by double-diffusion reaction of antiserum of cotton cultivar Giza 75 against antigens of $M$. phaseolina isolates $\left(\mathrm{no}_{\mathrm{s}} .4,5,6,7,8\right.$ and 20).

\begin{tabular}{lccccccc}
\hline \multirow{2}{*}{$\begin{array}{l}\text { Protein } \\
\text { fraction No. }\end{array}$} & \multicolumn{7}{c}{ Antiserum of Giza 75 x antigens of } \\
\cline { 2 - 8 } & Giza 75a & 4 & 5 & 6 & 7 & 8 & 20 \\
\hline 1 & + & + & - & - & - & - & - \\
2 & + & + & + & - & - & - & + \\
3 & + & + & + & - & - & - & + \\
4 & - & - & - & + & - & - & - \\
\hline
\end{tabular}

a Homologous antiserum-antigen reaction.

(+) The designated protein fraction was present.

(-) The designated protein fraction was absent.

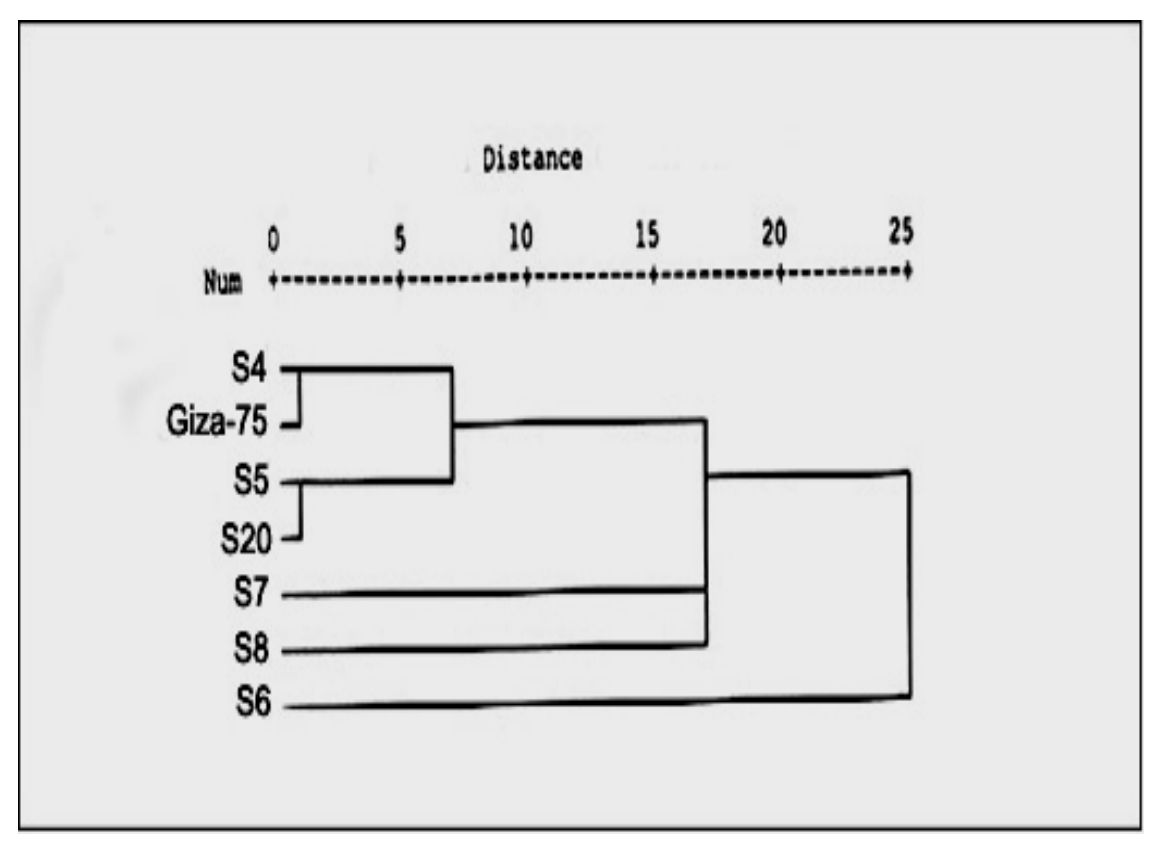

Fig. 9. Phenogram based on average linkage cluster analysis of serological protein patterns obtained by double - diffusion technique from 6 isolates of $M$. phaseolina from cotton when their antigens interacted against antiserum of cotton cultivar Giza 75. Characterization of isolates is shown in Table 1. 


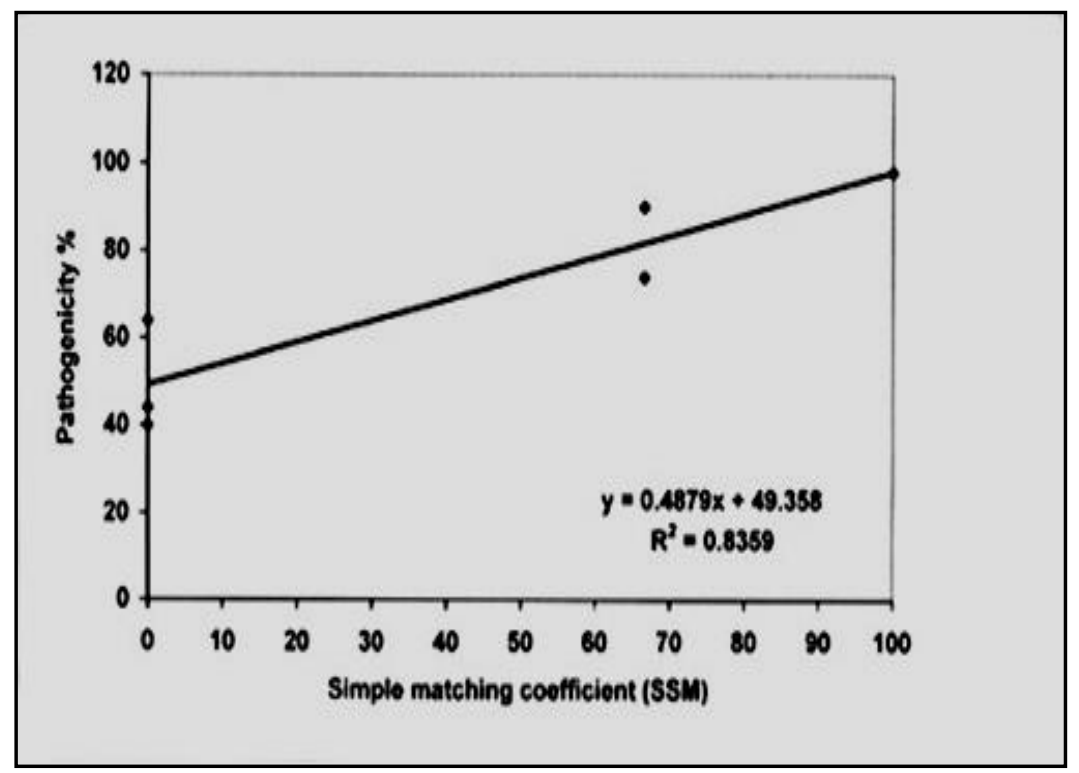

Fig. 10. Regression equation that describe the relationship between simple matching coefficient (SSM), established between isolates of $M$. phaseolina and cotton Giza 75, and pathogenicity of the isolates on this cultivar

\section{REFERENCES}

Ahmad, I., K. Burney and M. Aslam. 1991. Analysis of resistance in sunflower to charcoal rot pathogen Macrophomina phaseolina. Pakistan J. Bot. 23: 189-193.

Aly, A.A. 1988. Incidence of Fusarium wilt of flax as influenced by biotic and abiotic factors. Ph.D. Thesis. South Dakota State Univ., Brookings. $173 \mathrm{p}$.

Aly, A.A., E.M. Hussein, M.A. Mostafa, and A.I. Ismail. 1996. Distribution, identification, and pathogenicity of Fusarium spp. Isolated from some Egyptian cottons. Menofiya J. Agric. Res. 21: 819-836.

Aly, A.A., M.A. Abdel-Sattar, and M.R. Omar. 2006. Susceptibility of some Egyptian cotton cultivars to charcoal rot disease caused by Macrophomina phaseolina. J. Agric. Res. 21:819-836.

Barak, R., A. Maoz, and I. Chet. 1983. Antigenic differences among several Trichoderma isolates. Can. J. Microbiol. 31:810-816.

Bhatti, M.A. and J.M. Kraft. 1992. The effects of inoculum density and temperature on root rot and wilt of chickpea. Plant Dis. 76:50-54.

Chakraborty, B.N., and R.P. Purkayastha. 1987. Alteration in glyceollin synthesis and antigenic patterns after chemical induction of resistance in soybean to Macrophomina phaseolina. Canadian J. Microbiol. 33: 835-840. 
Charudattan, R., and J.E. DeVay. 1972. Common antigen among varieties of Gossypium hirsutum and isolates of Fusarium and Verticillium species. Phytopathology 62: 230-234.

Dhingra, O.D., and J.B. Sinclair. 1978. "Biology and pathology of Macrophomina phaseolina". Imprensia Universidade Federal de Viscosa, Brazil $166 \mathrm{p}$.

Hornok, L. 1980. Serotaxonomy of Fusarium species of the sections Gibbsum and Discolor. Trans. Brit. Mycol. Soc. 74: 73-78.

Hussein, E.M., A.A. Aly, A.Z.A. Ashour, and S.M. Nasr. 1996. Cluster analysis of serological protein patterns of three Fusarium species. J. Agric. Sci. Mansoura Univ. 21:3995-4012.

Hussein, E.M., A.A. Aly, M.A. Tag El-Din, and A.Z.A. Ashour. 1997. Comparative studies on serological and electrophoretic protein patterns of Rhizoctonia solani and its host and nonhost plants. J. Agric. Sci., Mansoura Univ. 22: 581-593.

lannelli, D., R. Capparelli, G. Cristinzio, F. Sala, and C. Noviello. 1982. Serological differentiation among formae speciales and physiological races of Fusarium oxysporum. Mycologia 74:313-319.

Kratka, J., B. Kynerova, A. Zemanova, and S. Sykorova. 1997. The diagnosis of Fusarium culmorum by polyclonal antibodies - preparation and character of antigens and antibodies. Ochrana Rostlin 33:89-102.

Lee, C.C., L.S. Bird, P.M. Thaxton, and M.L. Howell. 1986. The association of Macrophomina phaseolina with cotton. Acta Phytophylactica Sinica 13: 169-173.

Monga, D. and S. Raj. 1996. vertical screening against root rot of cotton in sick fileds . Crop Research Hisar 12 : 82-86.

Monga, D. and S. Raj. 2000. Screening of germplasm lines against root rot of cotton (G. hirsutum). Advances in Plant Sci. 13: 603-607.

Perez-Artes, E., M.I.G. Roncero, and R.M. Jimenes-Diaz. 1995. Restriction fragment length polymorphism analysis of the mitochondrial DNA of Fusarium oxysporum f.sp. ciceris. J. Phytopathology 143:105-109.

Porta-Puglia, A., P. Crino, and C. Mosconi. 1996. Variability in virulence to chickpea of an Italian population of Ascochyta rabiei. Plant Dis. 80: 39-41.

Purkayastha, R.P. and A. Ghosal. 1987. Immunoserological studies on root rot of groundnut (Arachis hypogaea L.). Canadian J. Microbiol. 33: 647-651.

Purkayastha, R.P.,and B.N. Chakraborty. 1983. Immunoelectrophoretic analysis of plant antigens in relation to biosynthesis of phytoalexin and disease resistance of soybean. Trop. Plant Sci. Res. 1: 89-96.

Rataj- Guranowska, M. and B. Wolko. 1991. Comparison of Fusarium oxysporum and Fusarium oxysporum var. redolens by analyzing the isozyme and serological patterns. J. Phytopathol. 132:287-293.

Rataj-Guranowska, M., I. Wiatroszak, and L. Hornok. 1984. Serological comparison of two races of Fusarium oxysporum f.sp. Iupini. Phytopathol. Z. 110:221-225.

Schilder, A.M.C., and G.C. Bergstrom. 1990. Variation in virulence within the population of Pyrenophora tritici-repentis in New York. Phytopathology 80: 84-90. 
Hussein, E.M. et al.

Turini, T.A., E.T. Natwick, G.G. Cook,and M.E. Stanghellini. 2000. Upland cotton varietal response to charcoal rot. Proc. the Beltwide Cotton Conf. Volume 1: $147-148$.

Turini, T.A., E.T. Natwick, and G.G. Cook. 2001. Upland cotton varietal response to charcoal rot. Proc. the Beltwide Cotton Conf. Volume 1: 140-141.

Watkins, G.M. ed. 1981. Compendium of Cotton Diseases. The American Phytopathological Society. St. Paul., Minnesota. 87p.

Wimalajeema, D.L.S., and J.E. DeVay. 1971. The occurrence and characterizatioon of a common antigen relationship between Ustilago maydis and Zea mays. Physiol. PI. Path. 1: 523-535.

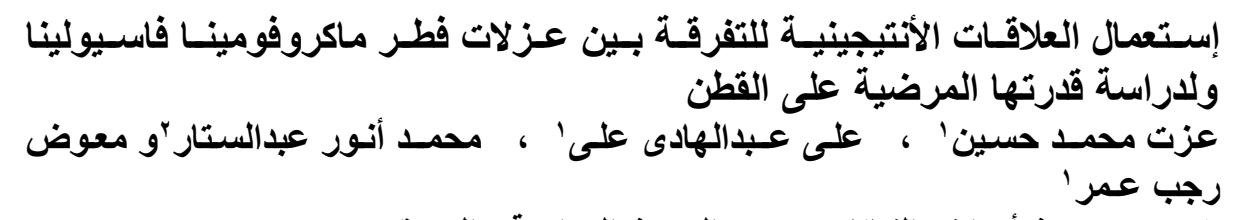

1- معهد بحوث أمراض النباتات ، مركز البحوث الزراعية ، الجيزة ، مصر.

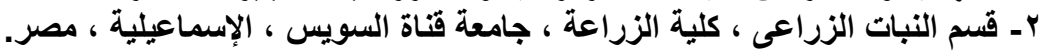

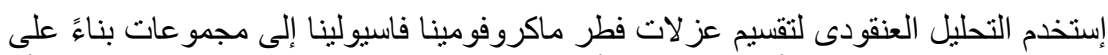

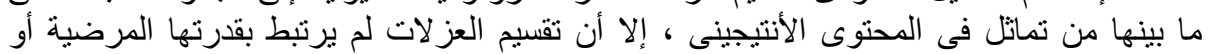

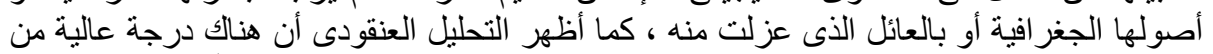

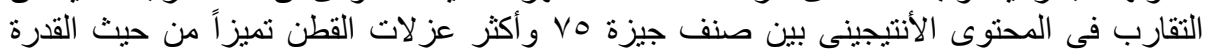

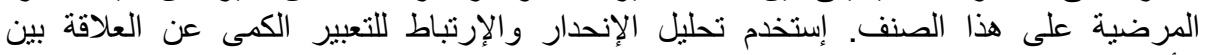

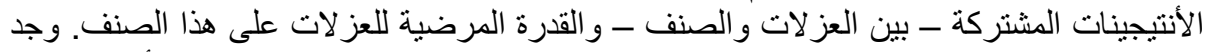

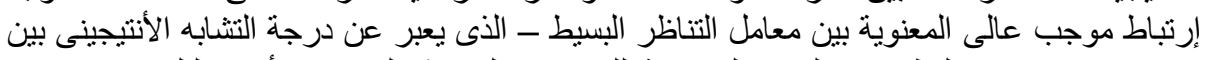

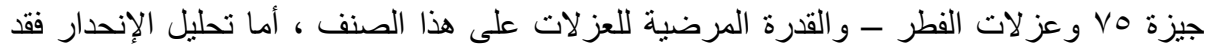

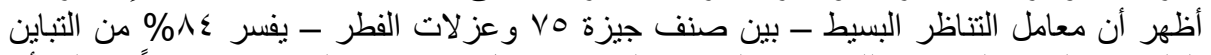

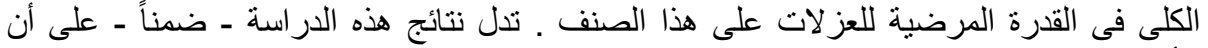

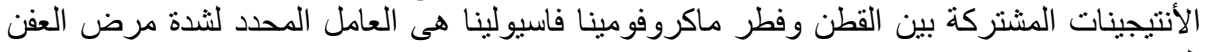

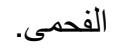

